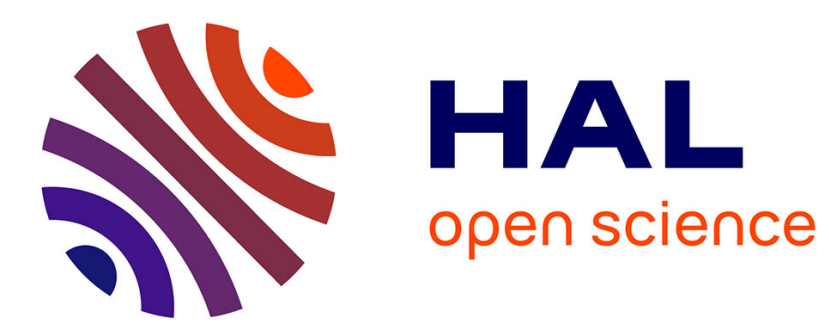

\title{
Numerical simulation of thermal fatigue behavior in a cracked disc of AISI H-11 tool steel
}

Faisal Qayyum, Masood Shah, Osama Shakeel, Fariha Mukhtar, Mehdi Salem, Farhad Rezai-Aria

\section{- To cite this version:}

Faisal Qayyum, Masood Shah, Osama Shakeel, Fariha Mukhtar, Mehdi Salem, et al.. Numerical simulation of thermal fatigue behavior in a cracked disc of AISI H-11 tool steel. Engineering Failure Analysis, 2016, 62, pp.242-263. 10.1016/j.engfailanal.2016.01.015 . hal-01799026

\section{HAL Id: hal-01799026 https://hal.science/hal-01799026}

Submitted on 24 May 2018

HAL is a multi-disciplinary open access archive for the deposit and dissemination of scientific research documents, whether they are published or not. The documents may come from teaching and research institutions in France or abroad, or from public or private research centers.
L'archive ouverte pluridisciplinaire $\mathbf{H A L}$, est destinée au dépôt et à la diffusion de documents scientifiques de niveau recherche, publiés ou non, émanant des établissements d'enseignement et de recherche français ou étrangers, des laboratoires publics ou privés. 


\title{
Numerical simulation of thermal fatigue behavior in a cracked disc of AISI H-11 tool steel
}

\author{
Faisal Qayyum $^{\mathrm{a}, *}$, Masood Shah ${ }^{\mathrm{a}, \mathrm{b}}$, Osama Shakeel ${ }^{\mathrm{a}}$, Fariha Mukhtar ${ }^{\mathrm{a}}$, \\ Mehdi Salem ${ }^{\mathrm{b}}$, Farhad Rezai-Aria ${ }^{\mathrm{b}}$ \\ a Department of Mechanical Engineering, University of Engineering and Technology, Taxila, Pakistan \\ ${ }^{\mathrm{b}}$ Université de Toulouse; INSA, UPS, Mines Albi, ISAE; ICA (Institut Clément Ader) Route de Tiellet, Campus Jarlard, Albi, France
}

Thermal fatigue is one of the key reasons of material failure in components which are exposed to high temperature cycles. Prediction of crack initiation site and crack propagation speed during thermal cycling helps us predict the life of a component in service. In this research numerical simulation of crack propagation due to thermal cycling on a circular disc has been carried out. The thermal profiles used in the simulation are taken from actual thermal fatigue experiments. The effect of the length of cracks and interaction between adjacent cracks has been investigated. 50 sets of numerical simulation models with different crack numbers and crack lengths have been simulated. The variation in Stress Intensity Factor (SIF), hoop stress and Crack Mouth Opening Displacement (CMOD) has been plotted as a function of primary/secondary crack lengths and number of cracks. Envelopes of possible crack growth have been identified and correspond well to the experimental observations. Results show a significant drop in hoop stress, SIF and CMOD with increase in number of cracks, thus limiting the number of cracks possible in a thermal fatigue crack network.

Keywords:

Thermal fatigue

Crack propagation

Numerical simulation

Stress Intensity Factor

Crack arrest

\section{Introduction}

Thermal fatigue is one of the key damage mechanisms in applications involving high temperatures like in power plants, engine valves, gas turbines, steam valves, nuclear reactors, high pressure die casting, and forging operations. Currently no standard procedure for thermal fatigue testing exists. The inherent complexity of thermal fatigue problem, renders standardization of this testing procedure almost impossible.

Different researchers have developed their own specific experimental setups, closely resembling the application being investigated. Some of the setups include a disc heated by induction on the periphery [1-12], triangular blade heated by induction [13], electrical heating of tube followed by water splashing to induce thermal shock [14-18], hot dipping of cylinders in molten aluminum [19,20], laser heating [21,22], focused halogen lamps heating [23,24], convection/combustion heating [25,26], furnace heating with water quenching $[27,28]$ and actual dies $[29,30]$. Out of these experimental setups most researchers have worked on the heated disc problem. Analytical models have been developed for heated disc type configuration using Stress Intensity Factor " $\Delta K$ " [31-35], for this purpose Mowbray et al. [31] used $\Delta K$ based on the weight function defined by Bueckner to characterize

\footnotetext{
* Corresponding author at: Fracture Mechanics and Fatigue Lab., Mechanical Engineering Department, University of Engineering and Technology, Taxila, Punjab, Pakistan.

E-mail address: faisal.qayyum@uettaxila.edu.pk (F. Qayyum).
} 


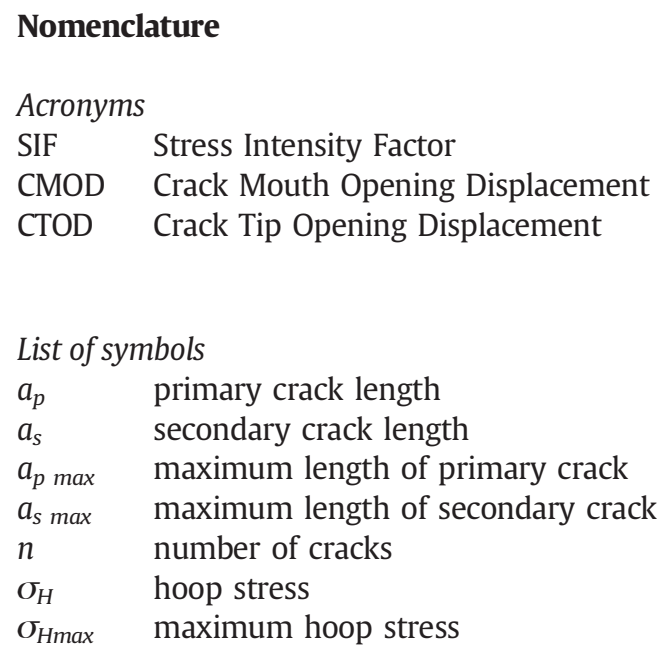

the thermal fatigue crack propagation [36]. Others used cyclic J integral [37,38] and strain intensity factor [32-35,39,40] for characterizing thermal fatigue crack propagation. Most researchers deal with thermal fatigue as a special case of isothermal fatigue. Many researchers have worked on numerical simulation models [41-43] to create better understanding of thermo-mechanical stresses which are produced during the process and are responsible for failure of components.

Thermal fatigue is considered to be composed of two components, initiation phase and the propagation phase. It has been investigated that the initiation might occur due to oxidation sites or due to plasticity, as in the case of stainless steels [unpublished internal results on thermal fatigue of 316 stainless steel, ecole mines albi]. One of the observations made during experimentation was that two diametrically opposed cracks initiate and propagate with almost the same speed through the specimens as represented in Fig. 1 schematics. Secondary cracks are created later and their propagation speed is lower than the primary cracks. The total number of cracks (primary and secondary) almost never exceeds 8 in number in oxidizing steel. This material was chosen because due to oxidation large number of cracks initiate, while the cracks having sufficient SIF propagate during thermal cycling. This phenomenon has been presented in Fig. 1.

This research aims to determine the interaction between primary and secondary cracks. It also aims to determine the threshold value of number of secondary cracks that can propagate. The threshold value is found to be dependent on the stress relaxation produced due to addition of secondary cracks around the periphery of the specimen.

All in all 50 simulation models with different crack number and crack lengths were run to determine the threshold of crack number. The drop in SIF, hoop stress and CMOD is plotted as a function of number of cracks and primary/secondary crack lengths. These plots give an envelope of propagation, clearly showing the parameters necessary for the crack propagation to occur. The results obtained were observed to be in agreement with the experimental observations.

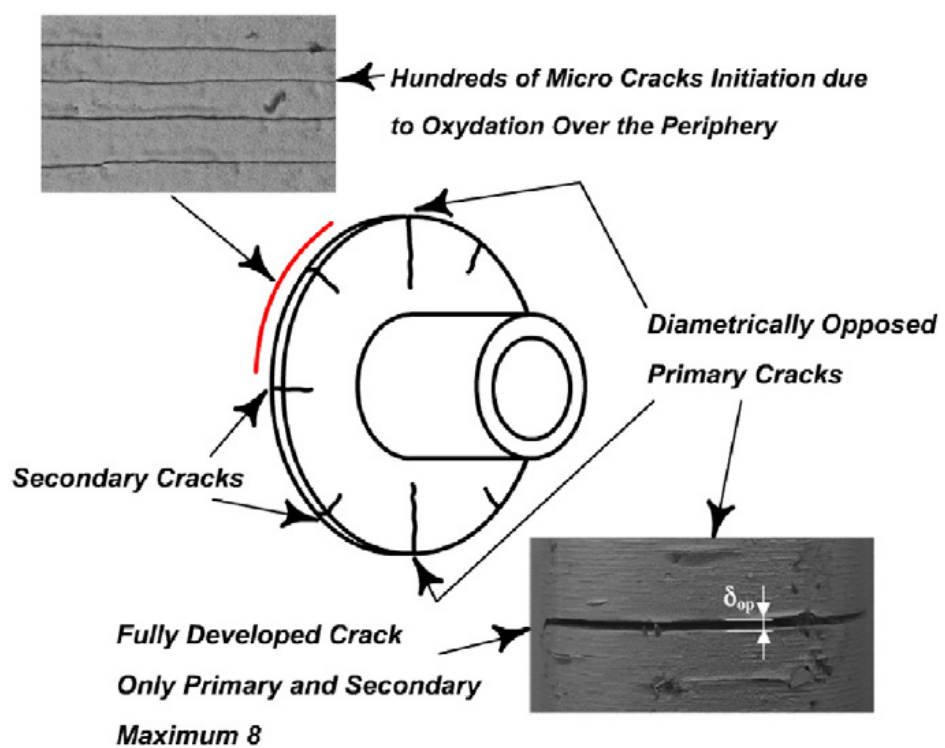

Fig. 1. Crack initiation and propagation in an oxidizing steel. 


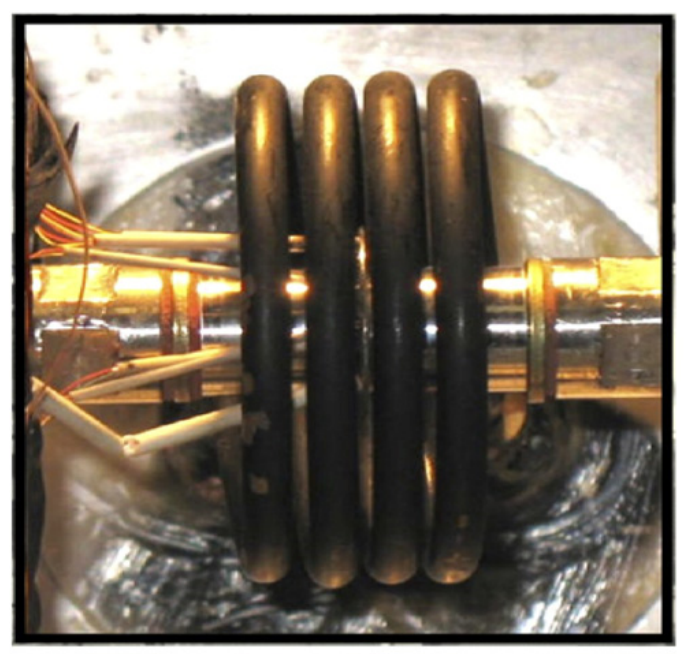

(a)

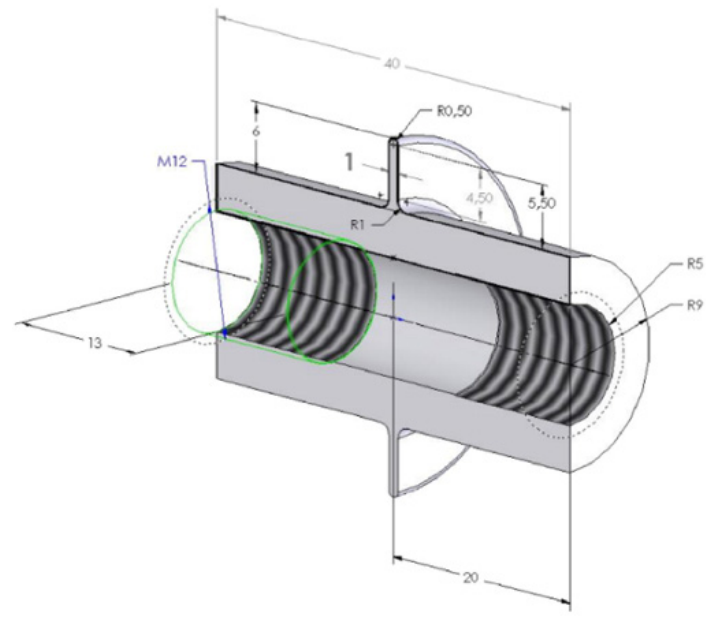

(b)

Fig. 2. (a) Experimental setup. (b) Specimen Shape (all dimensions are in mm) [44].

\section{Experimentation}

The experimentation was done by Salem M. [44] in his PhD thesis, and detailed material model for AISI H11 tool steel which have been incorporated in the numerical simulation model were developed by Ahmer [45]. The experimental setup and geometry of the used specimen is shown in Fig. 2. Heating was done by induction coils while cooling was done by cold water flowing through internal pipe at $25^{\circ} \mathrm{C}$. 6 thermocouples were spot welded on the disc at positions specified in Fig. 3. This specimen was heated using an induction heating system with $1.3 \mathrm{~s}$ heating cycle and $7.2 \mathrm{~s}$ cooling cycle. The resulting thermal profile is shown in Fig. 3 and is compared with the thermal profile obtained from simulation. The cracks were observed and measured using binocular microscope during testing, which helped in determining fatigue crack propagation rate and crack locations.

\section{Numerical simulation}

Numerical simulation was carried out on ABAQUS Standard ${ }^{\mathrm{TM}}$ 6.12. Decoupled thermo-mechanical approach was adopted during simulation. Simulations were carried out for a disc type specimen on a pipe configuration. Sectioned model of the assembly is shown in Fig. 2 (b). Thermal analysis was carried out for 10 thermal cycles to obtain steady state results which will be discussed

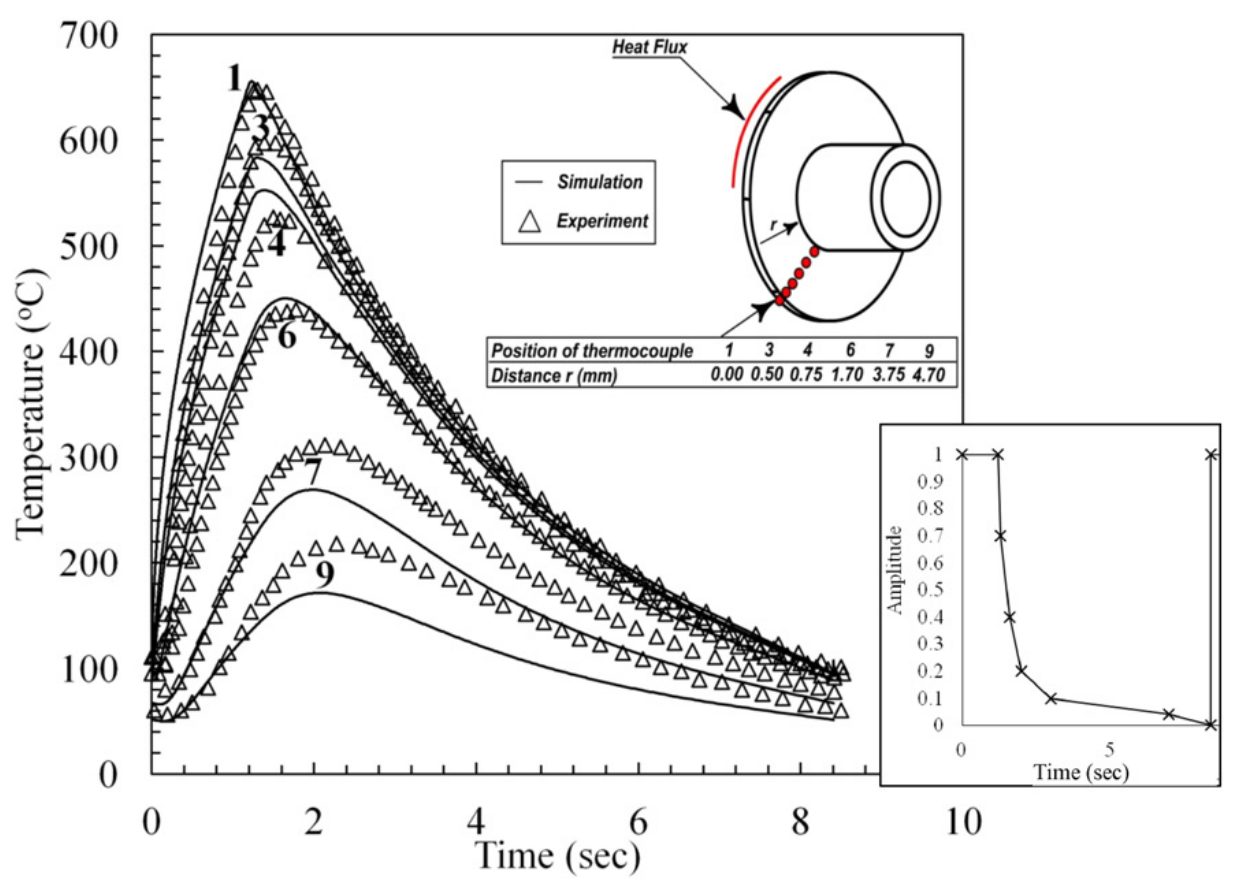

Fig. 3. Comparison of experimental and simulated thermal profile, and (inset figure) amplitude factor of maximum energy. 
later. Temperature change of each node was recorded after specific time intervals. Saved temperature changes at each node at specific time intervals were fed to the stress analysis file as an input. Results of stress development and crack opening during thermal cycling were observed.

Due to thermal cycling hundreds of microcracks develop on the surface of the specimen (upper left of Fig. 1). These microcracks are shown to be formed due to the presence of oxidation at the surface of the specimens. Some of these microcracks later develop into macro cracks (lower right of Fig. 1) and propagate through the section of the specimen. The primary cracks (minimal of $0.5 \mathrm{~mm}$ length), as they are called are the diametrically opposed cracks that appear initially and are always longer in length than the other cracks on the periphery of the specimen.

\subsection{Material data}

Specimen was made of AISI H-11 hot work tool steel with chemical composition as shown in Table 1. Density of $7840 \mathrm{~kg} / \mathrm{m}^{3}$ and a Poisson's ratio of 0.3 were used. The temperature dependent properties used during simulation are shown in Fig. 4.

\subsection{Thermal analysis}

The disc part of the specimen in Fig. 2 (b) was modeled as a 2D deformable shell of $30 \mathrm{~mm}$ outer diameter and $18 \mathrm{~mm}$ internal diameter with a thickness of $1 \mathrm{~mm}$. The hollow shaft inside was modeled as a 2D deformable shell of $18 \mathrm{~mm}$ outer diameter and $12 \mathrm{~mm}$ internal diameter having length $40 \mathrm{~mm}$ as shown in Fig. 5. Temperature dependent material properties of H11 tool steel (Fig. 4) were assigned to the material model. Both instances were assembled together in the assembly module by using coaxial constraint command. Transient heat transfer model was selected in step module for 10 thermal cycles giving a total time period of $85 \mathrm{~s}$ for the analysis. Heat sink of $25{ }^{\circ} \mathrm{C}$ was applied inside shaft. While defining boundary conditions, external surface of shaft and internal surface of disc were constrained with "tie interaction" of continuous heat transfer condition. Surface heat flux of $5.15 \mathrm{~W} / \mathrm{mm}^{2}$ was applied on the outer rim of flange with amplitude shown in Fig. 3. In Fig. 3, 1 means maximum flux and 0 means no flux. The amplitude profile values were adjusted so that the thermal profile obtained by simulation at different points along the radius of the disc matches the thermal profile in the experimentation. This indirectly takes into account the heating due to the induction coil, radiative losses, natural convection losses as well as the conduction loss due to the cooling channel. The comparison between experimental and numerical values is shown in Fig. 3. Close correlation exists up to a depth of 2 mm. After that the experimentation shows almost $20 \%$ higher temperatures than the numerical simulation. The amplitude follows the response of the induction heating system.

The meshed assembly is shown in Fig. 5. It was assured that aspect ratio of all elements is almost equal to 1 . The model was also checked for mesh dependency. The simulation model schematic is shown in Fig. 5. The thermocouple positions in Figs. 3 and 5 were used to calibrate the thermal model.

\subsection{Stress and fracture analysis}

For mechanical analysis the disc and shaft again modeled as 2D deformable shells with all properties as discussed in the Material data section. Temperature dependent material properties of H11 tool steel were assigned to the disc and shaft. An incremental plasticity model was used for the plastic deformation of the specimen.

The primary and secondary cracks of different lengths and numbers were modeled on disc using surface partition command. The choice of crack lengths follows the experimental observations. Initially the experiments were conducted on H11 steel. This steel develops an oxide scale due to thermal cycling and the detection of a crack under this scale was difficult. Also the crack initiation point is on the curve of the specimen. Both these factors affect the minimum resolution of the crack observations which is $0.5 \mathrm{~mm}$ using a binocular microscope. (Observations with higher powered microscopes are difficult due to low depth of field of the microscopes and heavily instrumented specimen, which has 6 thermocouples of $0.1 \mathrm{~mm}$ thickness spot welded on the surface).

Once the resolution is identified a complete range of possibilities of crack lengths is simulated. The only constraint was that the primary crack has to be longer than the secondary crack length. A 16 cracks numerical simulation set containing 1 primary crack of $2 \mathrm{~mm}$ length and 15 secondary cracks of $0.5 \mathrm{~mm}$ length is shown in Fig. 6. Cracks were defined in assembly module using contour integral command. Collapsed element side seam with mid side node parameter of 0.24 was defined for all cracks. The set of cracks defined during simulation are shown in Table 2. Static general model was selected in step module for time period of $85 \mathrm{~s}$ which simulates 10 thermal fatigue cycles. It was observed that although the thermal profile stabilizes at the third cycle, the stress-strain response and the J-integral does not stabilize up to the 7th cycle. It was thus decided to run the thermal fatigue experiments up to 10 cycles so that stability in mechanical response can be assured. Due to cyclic simulation the crack faces come into contact during the simulation. The crack faces were defined as contact pairs with frictionless contact to avoid

Table 1

Chemical composition of AISI H-11 tool steel.

\begin{tabular}{lllllllllll}
\hline Elements & $\mathrm{Cr}$ & $\mathrm{Mo}$ & $\mathrm{Si}$ & $\mathrm{V}$ & $\mathrm{C}$ & $\mathrm{Ni}$ & $\mathrm{Cu}$ & $\mathrm{Mn}$ & $\mathrm{P}$ & $\mathrm{S}$ \\
\hline wt.\% & $4.75-5.50$ & $1.10-1.75$ & $0.80-1.20$ & $0.80-1.20$ & $0.32-0.45$ & 0.3 & 0.25 & $0.20-0.50$ & 0.03 & 0.03 \\
\hline
\end{tabular}




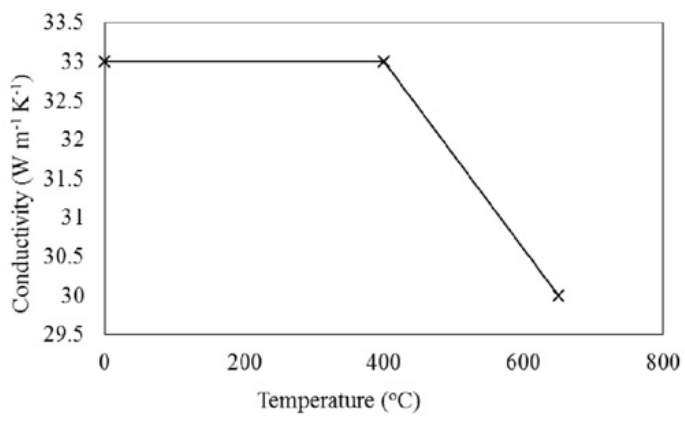

Conductivity as function of temperature

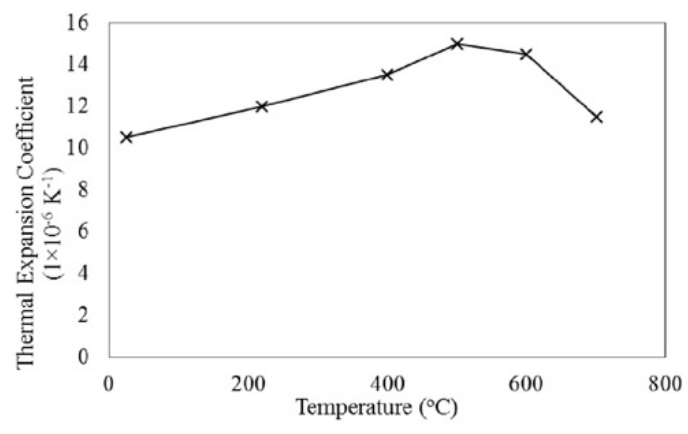

Thermal expansion coefficient as function of temperature

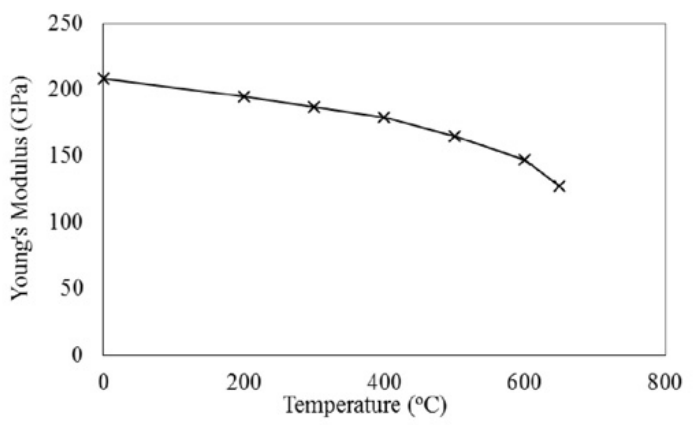

Modulus of elasticity as function of temperature

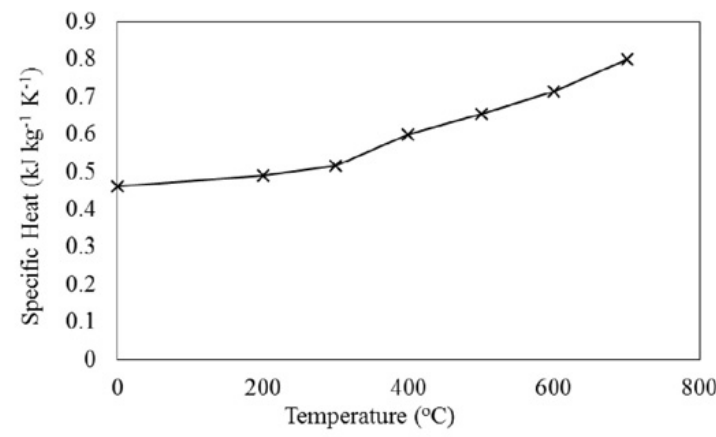

Specific heat as function of temperature

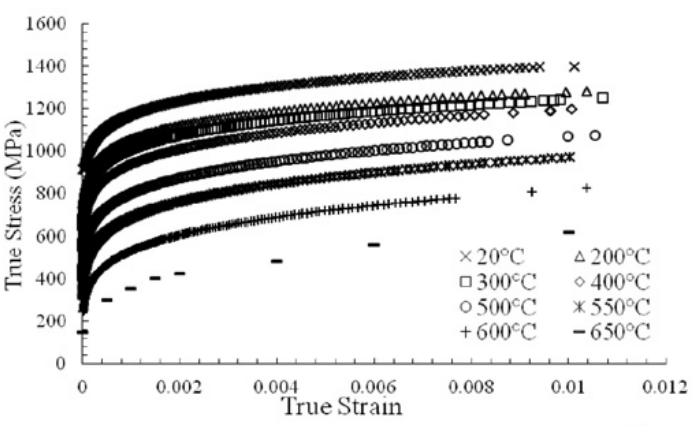

Temperature dependent plastic strain data at $10^{-3}$ strain $\mathrm{s}^{-1}$

Fig. 4. Temperature dependent material data of $\mathrm{H}-11$ tool steel $[44,45]$.

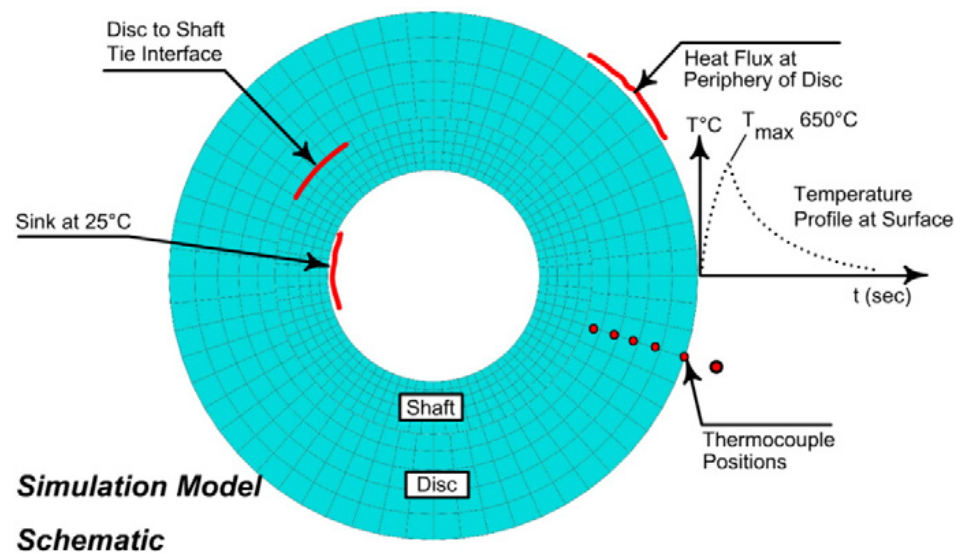

Fig. 5. Meshed assembly of disk and shaft. 


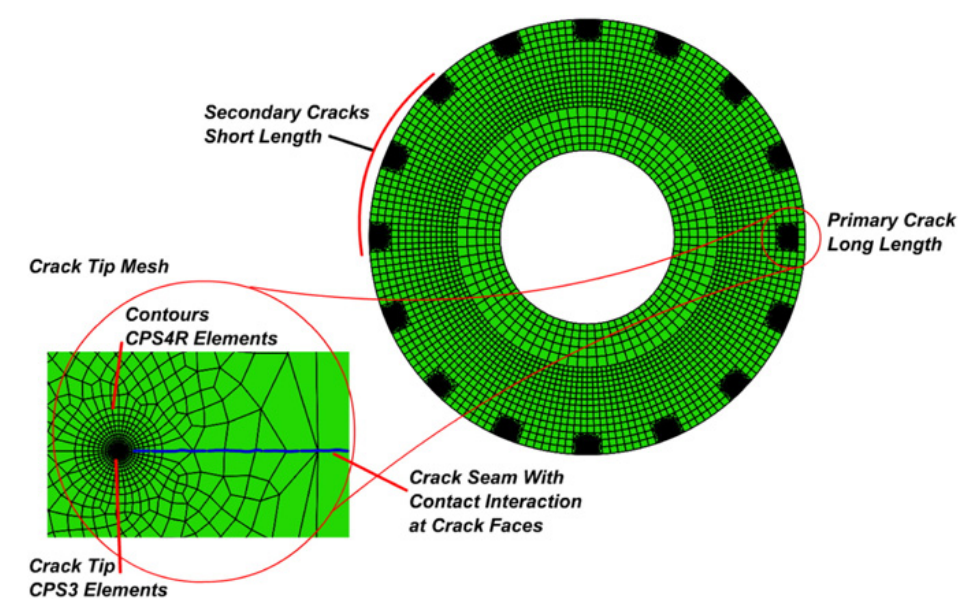

Fig. 6. Meshed assembly of simulation set containing 1 primary crack of $2 \mathrm{~mm}$ length and 15 secondary cracks of $0.5 \mathrm{~mm}$ length.

any elemental penetration during the simulation. Coefficient of friction is considered as frictionless because in mode I crack no sliding occurs. Since the simulation model is based on mode I crack opening configuration, keeping in view the simplicity of the model, the effect of sliding was not considered and hence frictionless contacts were defined.

The detailed meshing for crack tip is given elsewhere [46]. The meshed assembly is shown in Fig. 6. In total, 1 thermal and 49 mechanical simulation models were run to achieve the desired results.

\section{Results and discussion}

Thermal fatigue is caused by thermal gradients in a component which results in material expansion and strains eventually resulting in production of thermal stresses in the component due to the constraint of the material itself. The phenomenon is majorly strain controlled deformation. As a consequence the largest strains and stresses occur at the surface with thermal cycling, because of which a large number of cracks initiate at the surface. When the components (in this case a disc) develop cracks, its compliance increases, which leads to reduction of the stresses and strains. When this happens the formation of new cracks becomes less likely and the propagation of individual macro-cracks is reduced. The reduction in stresses/strains is directly linked to the circumferential distance between cracks and the crack depth, which results in a typical number of cracks. Due to the thermal gradients the stresses also decay with the distance from the heated surface. As a consequence crack propagation rate slows down and crack often arrests at a specific depth.

Numerical simulation gives us an insight of how heat transfer takes place during each cycle, and in response to cyclic thermal fatigue how mechanical stresses are produced in the disc. It is also observed how number of cracks $(n)$ and crack lengths $\left(a_{s}\right.$ and $\left.a_{p}\right)$ affect the stresses produced in the disc. The thermal cycle stabilizes typically at the third cycle in simulation and experimentation alike. Fig. 3 also shows the comparison of the experimental and numerical thermal response and a good correlation is observed. In this section the stress-strain response is discussed followed by the effects of multi-cracking on the stress distribution and J-integral ahead of the crack tip.

Table 2

Set of cracks defined during simulation.

\begin{tabular}{|c|c|c|c|}
\hline $\begin{array}{l}\text { Number of cracks } \\
(\mathrm{n})\end{array}$ & $\begin{array}{l}\text { Length of primary crack } \\
\left(a_{p}\right)\end{array}$ & $\begin{array}{l}\text { Length of secondary cracks } \\
\left(\mathrm{a}_{\mathrm{s}}\right)\end{array}$ & Total number of simulations \\
\hline 1 & $0.5,1,2,3,4$ & 0 & 5 \\
\hline \multirow[t]{4}{*}{2} & $0.5,1,2,3,4$ & 0.5 & 11 \\
\hline & $2,3,4$ & 1 & \\
\hline & 3,4 & 2 & \\
\hline & 4 & 3 & \\
\hline \multirow[t]{4}{*}{4} & $0.5,1,2,3,4$ & 0.5 & 11 \\
\hline & $2,3,4$ & 1 & \\
\hline & 3,4 & 2 & \\
\hline & 4 & 3 & \\
\hline \multirow[t]{4}{*}{8} & $0.5,1,2,3,4$ & 0.5 & 11 \\
\hline & $2,3,4$ & 1 & \\
\hline & 3,4 & 2 & \\
\hline & 4 & 3 & \\
\hline \multirow[t]{4}{*}{16} & $0.5,1,2,3,4$ & 0.5 & 11 \\
\hline & $2,3,4$ & 1 & \\
\hline & 3,4 & 2 & \\
\hline & 4 & 3 & \\
\hline
\end{tabular}




\subsection{Stress-strain response}

The stress-strain response is studied initially on the un-cracked disc. This response is important in determining the crack initiation sites. Isotropic hardening temperature dependent material model was used. The first cycle shows a large amount of plastic deformation in compression. The initial heating results in expansion of the material which results in axial compression of flange, and the compressive stress increases till the temperature reaches $525{ }^{\circ} \mathrm{C}$. Beyond this temperature, although the expansion continues, the yield strength of the material starts to drop. $550{ }^{\circ} \mathrm{C}$ presents the first tempering temperature of this material and is also considered to be the limit of hot hard behavior. This softening results in a large amount of plastic deformation and reduction in compressive stress, visible is hoop stress vs temperature plot Fig. 7. The drop in stress is substantial, from $820 \mathrm{MPa}$ to $530 \mathrm{MPa}$ compressive.

As the disc cools, a tensile residual stress is observed due to yielding in the first cycle. It is believed that this tensile residual stress is responsible for the thermal fatigue cracking in metals. After the first few cycles, the plastic deformation is greatly reduced and the stress-strain curve stabilizes. However, there is some amount of plastic deformation in each cycle. This plastic deformation eventually causes enough damage to initiate thermal fatigue cracks.

\subsection{Drop of tensile stress in flange due to multiple cracks}

The presence of cracks affects the hoop stresses produced at the edge of the disc. Fig. 8 (a, b, c, d) represents the smallest primary crack length and secondary crack length of the simulation. Minimal (almost non-existent) effect of increase in number of cracks ( $\mathrm{n}$ ) on the periphery of the disc during compression cycle is observed. However, the effect of the number of cracks (n) on the tension part of the stress-strain response is significant. In Fig. 8 (a) it can be observed that there is a drop in tensile stress where the cracks are present. However, between these points there is a large "plateau" of constant tensile stress. For 4 cracks (Fig. 8 (b)) the "plateau" still exists, however the maximum value of the tensile stress slightly drops. It is seen that for 8 cracks (Fig. 8 (c)) there is almost no constant stress zone left on the periphery of the crack. Also, the value of the maximum tensile stress drops from $340 \mathrm{MPa}$ to $320 \mathrm{MPa}$. This shows that the tensile stress peaks (that would exist in case of the uncracked specimen) are now completely relieved by the 8 cracks around the periphery. A further increase in the number of cracks to 16 (Fig. 8 (d)) reduces the tensile stress peaks to $280 \mathrm{MPa}$ and there is no "plateau" showing that the tensile stress that initially caused the crack initiation cannot be achieved now. This is in agreement with experimental results [44] where the maximum number of cracks ever achieved never cross 8.

Fig. 9 shows the comparison for long cracks as well. It is seen that for maximum crack length the tensile stress values drop to $120 \mathrm{MPa}$ in the case of 16 cracks, thus eliminating any possibility of having more than 8 cracks to propagate around the periphery. The difference in compressive stresses between $a_{p}=1 \mathrm{~mm}$ (lower compressive stress) and $\mathrm{a}_{\mathrm{p}}=4 \mathrm{~mm}$ (higher compressive stress) is due to the numerical model that has been used. The contact of the crack faces is necessary to accurately simulate the compressive stresses. In the numerical model, contact of the crack faces is made except for the last element of the crack tip. Here the contact cannot be defined because the upper and lower face has an intersecting point (crack tip). During simulation, the crack tip elements cross each other. The simulation generally gives satisfactory results because the area represented by the crack tip is much lesser than the total crack faces. But in the case of very short cracks, the effect of this (non-contact definition) is slightly more pronounced. The effect is manifested as a lower compressive stress simulated. In the extreme cases as is shown in Fig. 9 this error is almost $8 \%$.

The J-integral calculations are important during the tensile cycle of the TF experiment. This difference of compressive stress might not greatly affect the J-integral values.

\subsection{J-integral as a function of crack length}

Once the cracks initiate, they will continue to propagate under the effects of the tensile stress. The crack propagation speed has been found to be fast up to $1 \mathrm{~mm}$ crack length and slows down considerably afterwards. The primary crack propagation arrests at

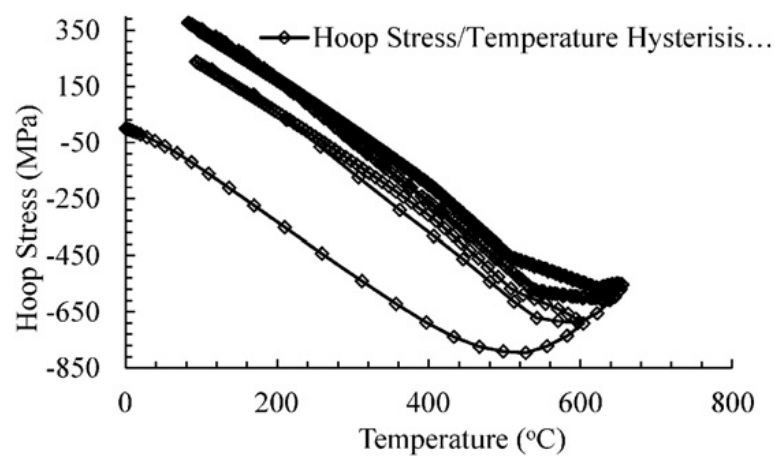

Fig. 7. Hoop stress vs temperature curve. 


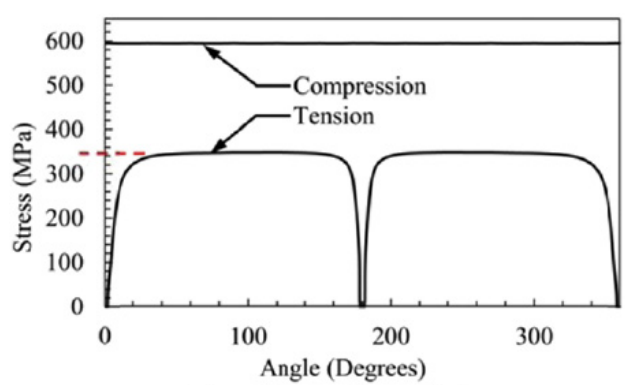

(a) $\mathrm{n}=2, \mathrm{a}_{\mathrm{p}}=1, \mathrm{a}_{\mathrm{s}}=0.5$

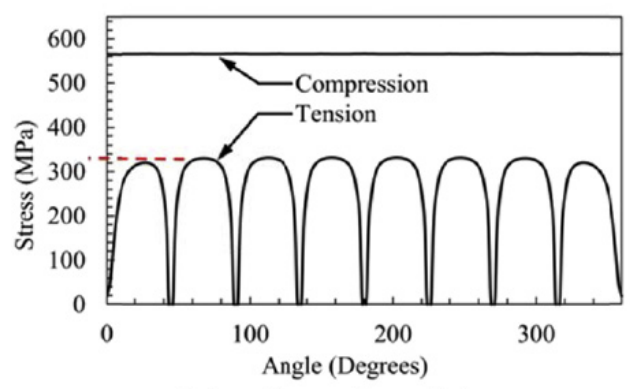

(c) $\mathrm{n}=8, \mathrm{a}_{\mathrm{p}}=1, \mathrm{a}_{\mathrm{s}}=0.5$

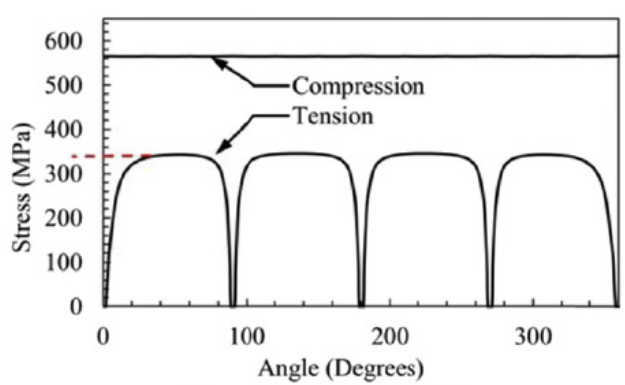

(b) $\mathrm{n}=4, \mathrm{a}_{\mathrm{p}}=1, \mathrm{a}_{\mathrm{s}}=0.5$

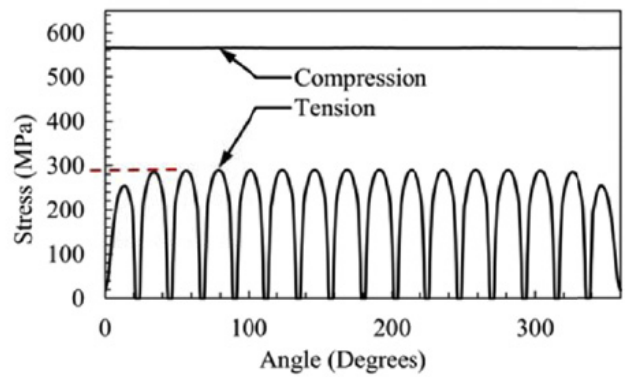

(d) $\mathrm{n}=16, \mathrm{a}_{\mathrm{p}}=1, \mathrm{a}_{\mathrm{s}}=0.5$

Fig. 8. Distribution of hoop stress along periphery of the flange.

a length of $3.5 \mathrm{~mm}$ maximum while the secondary cracks rarely exceed $2.5 \mathrm{~mm}$ in length. Fig. 10 [44] shows some of the results obtained experimentally (in this case only five cracks were tracked while others do exist, but they were not tracked).

\subsection{Development of crack tip stress field}

When a crack is introduced into the periphery, it initially acts as an un-cracked ligament during the first heating cycle. Following this during the cooling cycle the initial yielding at the highest temperature causes tensile stresses which open the crack as shown in the Fig. 11. The second cycle causes crack closure (forward yielding) and then during subsequent cooling (second cycle) a more severe crack opening is observed.

The contour integral plot in Fig. 12 represents the development of crack tip stress field. Sharp rise in the second cycle as compared to the first cycle is indicative of the residual crack opening created due to first yielding of the cracked specimen (Fig. 12). The numerical simulation of the contour integral shows that the J-integral remains constant, (and high) up to $1 \mathrm{~mm}$ crack length (Fig. 12). Beyond this point the value sharply reduces and is minimal at $3 \mathrm{~mm}$ crack length. At $4 \mathrm{~mm}$ crack length the value is almost zero, indicating that there is not much possibility of crack growth at this crack length. This fact is experimentally verified with experimentally obtained crack lengths [44].

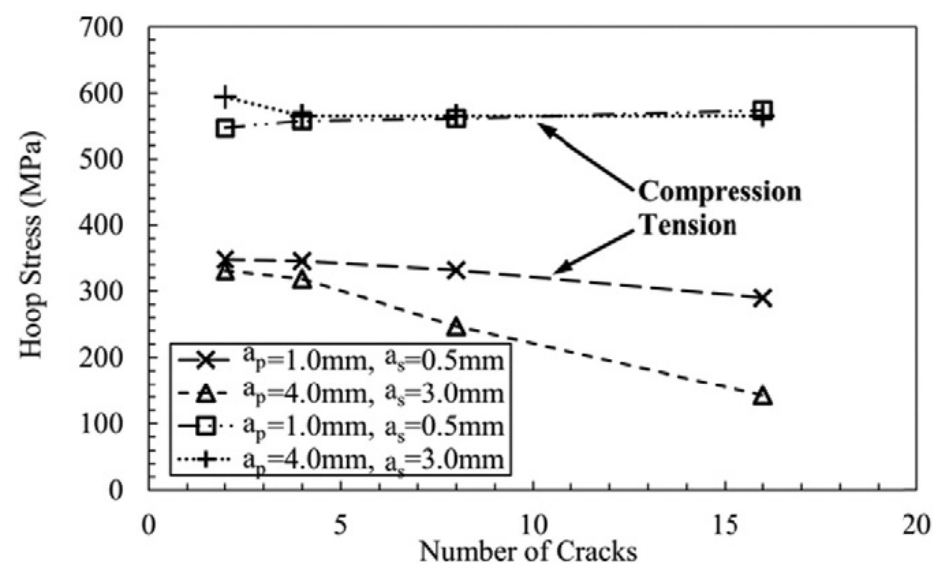

Fig. 9. Comparison of $\sigma_{H \max }$ at periphery of disk as a function of $n, a_{s}$ and $a_{p}$. 


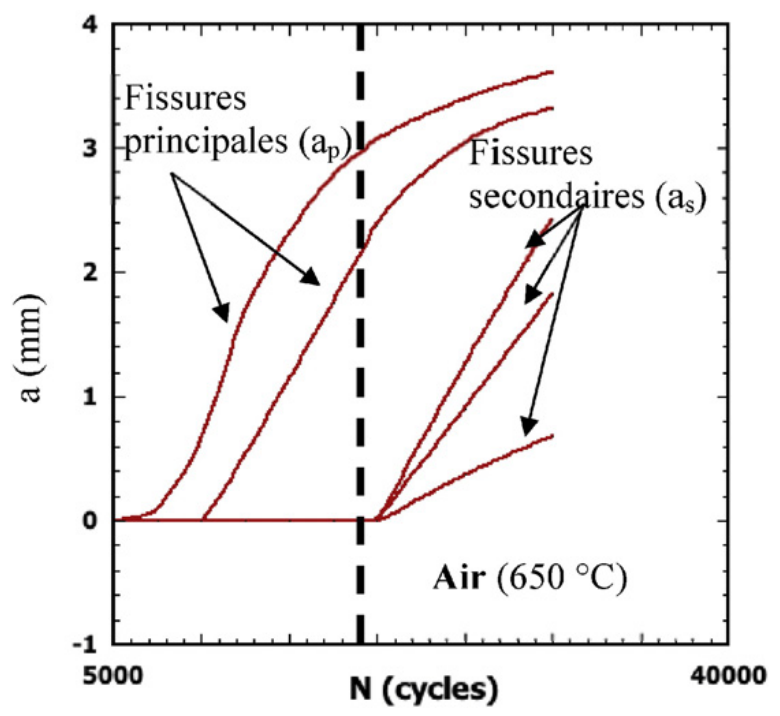

Fig. 10. Crack growth in disc specimen. Primary cracks are longer than the secondary cracks. $\mathrm{a}_{\mathrm{pmax}}=3.5 \mathrm{~mm}$, $\mathrm{a}_{\mathrm{smax}}=2.5 \mathrm{~mm}$. Cracks accelerate up to $1 \mathrm{~mm}$ length [44].

\subsection{Envelopes of crack propagation}

The effect of the number of secondary cracks of $0.5 \mathrm{~mm}$ length on the J-integral of the primary crack is shown in the surface plot in Fig. 13 (a). The red and light blue shades within $0 \leq n \leq 7$ (where $n=$ number of secondary cracks) shows the envelope of propagation. Beyond $\mathrm{n}=7$ there is a sharp drop in the J-integral value that would arrest any crack. Also beyond $\mathrm{a}_{\mathrm{p}}=3 \mathrm{~mm}$ the J-integral value drops to zero, indicating that no propagation is possible. Parallel surfaces can be obtained for different values of $\mathrm{a}_{\mathrm{s}}$. In the same manner the J-integral surface plot for the other extreme condition with $\mathrm{a}_{\mathrm{p}}=4 \mathrm{~mm}$ and different $\mathrm{a}_{\mathrm{s}}$ is shown in Fig. 13 (b). It is clear here that the blue part of the surface indicates the zone of non-propagation. This surface shows that the maximum secondary crack length could not exceed $2.5 \mathrm{~mm}$. Practically this observation seems to be true by experimental verification [44].

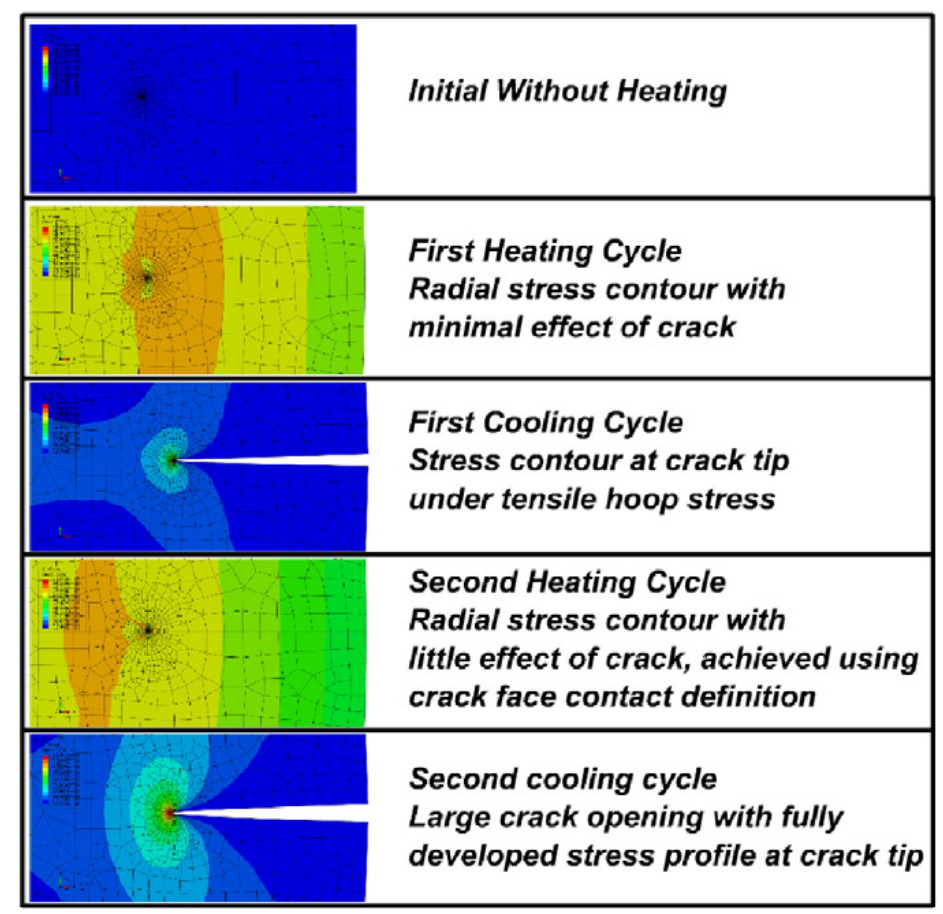

Fig. 11. Complete development of a crack tip stress field in two consecutive thermal cycles. 


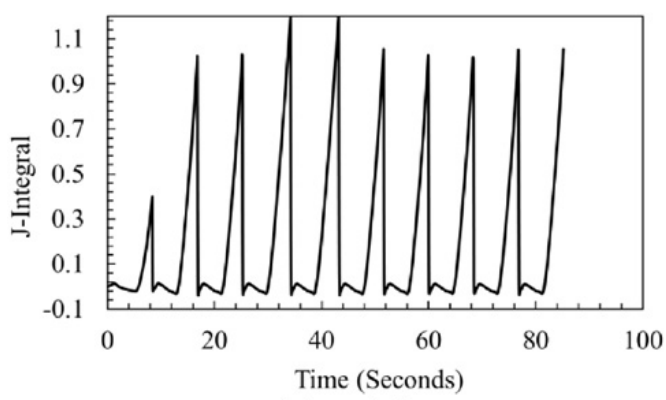

(a) $a_{p}=0.5$

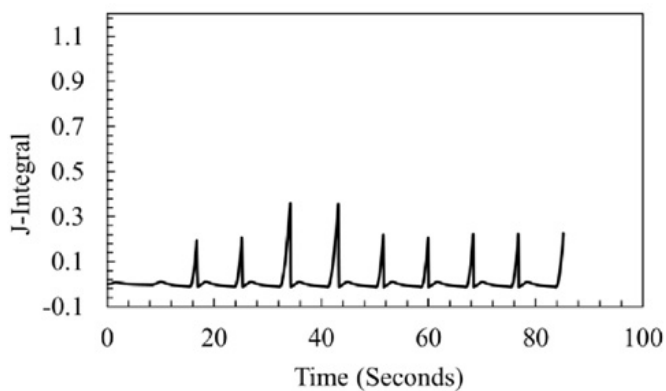

(c) $a_{p}=2.0$

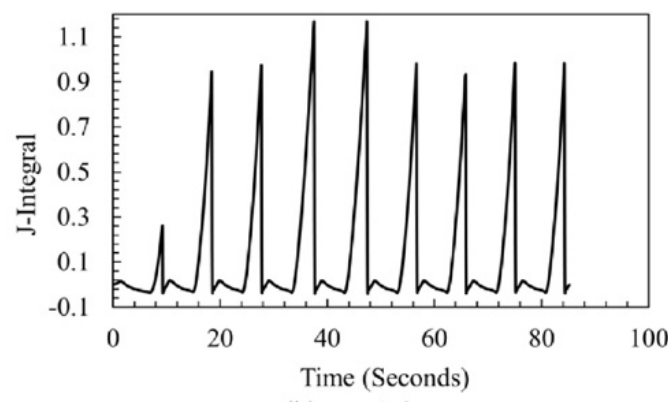

(b) $\mathrm{a}_{\mathrm{p}}=1.0$

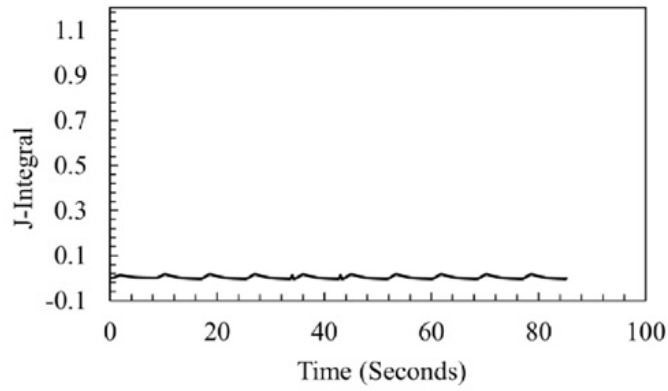

(d) $a_{p}=3.0$

Fig. 12. J-integral stabilization graph when primary crack length $\mathrm{a}_{\mathrm{p}}=0.5,1.0,2.0$ and $3.0 \mathrm{~mm}$.

\subsection{CMOD as a function of $a_{p}$ and $a_{s}$}

Numerous researchers have worked on relating the fatigue crack growth rate to cyclic J-integral [47-49] [50] and to the Crack Tip Opening Displacement (CTOD) [24,51-54]. The ASTM standard E399 [55] also gives an indirect crack length measurement method using the CMOD. The CMOD values were thus extracted for the different thermal cycles to see if they represent the Jintegral values at the crack tip as shown in Fig. 14 (a) and (b).

It is seen that the CMOD values of the primary or secondary crack do not represent at all whatever is happening at the crack tip. The values of the CMOD increase continuously while the crack propagation rate and J-integral drop continuously during the propagation beyond $1 \mathrm{~mm}$ crack length. The CMOD values do not change a lot even for 16 cracks when the secondary cracks have small length (Fig. 14 (a)). CMOD values for 16 cracks shows a sharp decline, which is representative of stress relaxation around the periphery for longer crack lengths.

\section{Conclusion}

The study to verify the limiting number of cracks produced on the rim of an $\mathrm{H} 11$ tool steel disc exposed to thermal fatigue was carried out using numerical simulation technique. Decoupled thermal mechanical numerical simulation technique was successfully used to get an insight of a thermal fatigue phenomenon. Thermal profiles were taken from actual thermal fatigue experiments. Isotropic hardening temperature dependent material model was used. 50 sets of numerical simulation models with different crack numbers and crack lengths were simulated to determine the interaction between the primary and secondary cracks. Significant

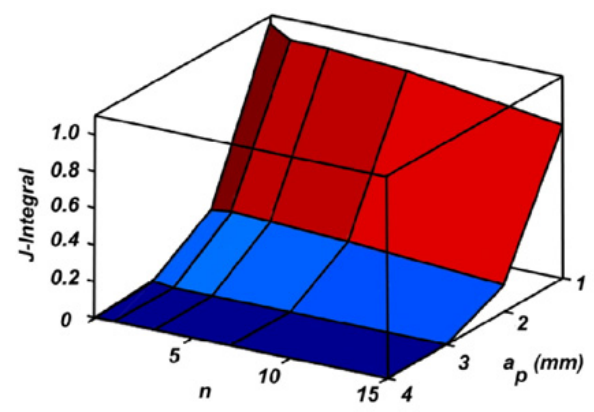

(a) Primary Crack with as $=0.5 \mathrm{~mm}$

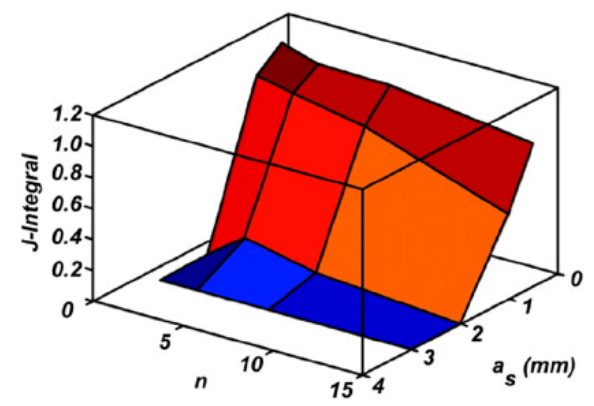

(b)Secondary crack with ap $=4 \mathrm{~mm}$

Fig. 13. Surface plot of J-integral as a function of, (a) $a_{p}, n$ and (b) $a_{s}, n$. 

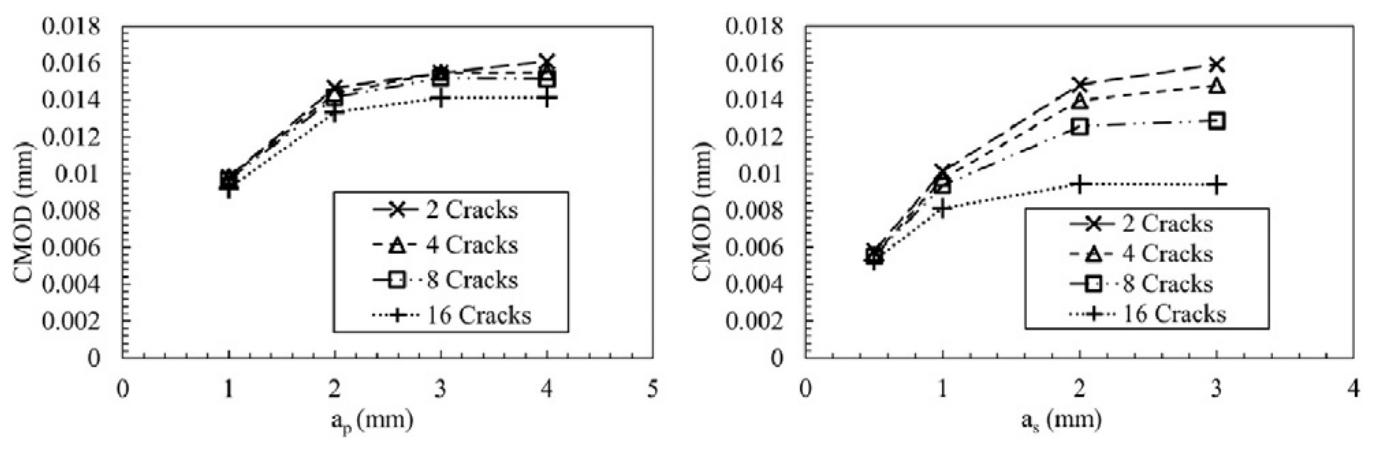

Fig. 14. (a) CMOD vs $a_{p}$ when $a_{s}=0.5 \mathrm{~mm}$ length, (b) CMOD vs $a_{s}$ when $a_{p}=4.0$ mm length.

drop in hoop stress and SIF with increase in number of cracks was observed. Envelopes of crack propagation were determined by plotting surface plots of J-integral as a function of $n, a_{p}$ and $a_{s}$.

1. It was observed that the initial heating causes expansion of the material which results in axial compression of flange, and the compressive stress increases till the temperature reaches $525{ }^{\circ} \mathrm{C}$. Beyond this temperature yield strength starts to drop which softens the material and results in drop of compressive stress. 35\% drop in compressive stress was observed for first cycle in Fig. 7 (from $820 \mathrm{MPa}$ to $530 \mathrm{MPa}$ compressive) which is considered to be the most damaging.

2. It is obvious that crack initiation and propagation in the disc occurs due to tensile stresses. It was observed that increases in number of cracks produced in the disk substantially decreases maximum tensile stresses on the rim which limits the number of cracks produced due to the phenomena of stress relieving. In the current scenario it was observed that the number of cracks propagating will never exceed 8.

3. It was observed that crack tip stress field fully develops after multiple fatigue cycles. It was also observed that value of Jintegral on crack tip decreases with increase in crack length. To elaborate this phenomenon of crack arrest surface plots of $\mathrm{J}$-integral as a function of $\mathrm{n}, \mathrm{a}_{\mathrm{p}}$ and $\mathrm{a}_{\mathrm{s}}$ were developed to find the crack propagation envelopes for primary and secondary crack lengths. As the maximum number of cracks never cross the value of 8 the primary crack length never exceeds $3 \mathrm{~mm}$ and secondary crack lengths never cross $2.5 \mathrm{~mm} . \mathrm{n} \leq 8, \mathrm{a}_{\mathrm{p}} \leq 3 \mathrm{~mm}$ and $\mathrm{a}_{\mathrm{s}} \leq 2.5 \mathrm{~mm}$, these are considered to be the threshold values.

4. It was observed that although the value of J-integral drops as the crack length increases, the CMOD keeps on increasing. It is concluded that in the current scenario CMOD does not represent a good measure of the crack tip stresses.

\section{Acknowledgment}

Experimentation of this research was conducted at the Universite de Toulouse; INSA, UPS, Mines Albi, ISAE; ICA (Institut Clément Ader) Route de Tiellet, Campus Jarlard, Albi, France. The simulation was done at the Fracture Mechanics and Fatigue Lab., Department of Mechanical Engineering, University of Engineering and Technology Taxila (UET/ASR\&TD/RG-1250 and UET/ASR\&TD/ RG-348), Pakistan. The study was funded and supported by both institutes which are gratefully acknowledged.

\section{Appendix A. Supplementary data}

Supplementary data to this article can be found online at http://dx.doi.org/10.1016/j.engfailanal.2016.01.015.

\section{References}

[1] S. Le Roux, et al., Image analysis of microscopic crack patterns applied to thermal fatigue heat-checking of high temperature tool steels, Micron 44 (0) (2013) 347-358.

[2] M. Kamaya, M. Kawakubo, Loading sequence effect on fatigue life of Type 316 stainless steel, Int. J. Fatigue 81 (2015) 10-20.

[3] F. Szmytka, et al., Thermal fatigue analysis of automotive diesel piston: experimental procedure and numerical protocol, Int. J. Fatigue 73 (0) (2015) 48-57.

[4] K. Kuwabara, A. Nitta, Thermal-mechanical low-cycle fatigue under creep-fatigue interaction on type 304 stainless steels, Fatigue Fract. Eng. Mater. Struct. 2 (3) (1979) 293-304.

[5] C. Robertson, M.C. Fivel, A. Fissolo, Dislocation substructure in 316 L stainless steel under thermal fatigue up to 650 K, Mater. Sci. Eng. A 315 (1-2) (2001) $47-57$.

[6] A. Persson, S. Hogmark, J. Bergström, Simulation and evaluation of thermal fatigue cracking of hot work tool steels, Int. J. Fatigue 26 (10) (2004) $1095-1107$.

[7] J. Sjöström, J. Bergström, Thermal fatigue testing of chromium martensitic hot-work tool steel after different austenitizing treatments, J. Mater. Process. Technol. $153-154$ (0) (2004) 1089-1096.

[8] A. Persson, S. Hogmark, J. Bergström, Thermal fatigue cracking of surface engineered hot work tool steels, Surf. Coat. Technol. 191 (2) (2005) $216-227$.

[9] E. Paffumi, K.F. Nilsson, N.G. Taylor, Simulation of thermal fatigue damage in a 316 L model pipe component, Int. J. Press. Vessel. Pip. 85 (11) (2008) $798-813$.

[10] A. Fissolo, et al., Crack initiation under thermal fatigue: an overview of CEA experience. part I: thermal fatigue appears to be more damaging than uniaxial isothermal fatigue, Int. J. Fatigue 31 (3) (2009) 587-600.

[11] S. Le Roux, et al., Role of heat-flux density and mechanical loading on the microscopic heat-checking of high temperature tool steels under thermal fatigue experiments, Int. J. Fatigue 51 (2013) 15-25 (0).

[12] F. Medjedoub, et al., Effect of local stress on the heat-checking morphology in high temperature tool steels under thermal fatigue: transition from multi-axiality to uniaxiality, Mech. Mater. 69 (1) (2014) 159-172.

[13] F. Rezai-Aria, L. Remy, An oxidation fatigue interaction damage model for thermal fatigue crack growth, Eng. Fract. Mech. 34 (2) (1989) $283-294$. 
[14] A. Fissolo, et al., Thermal fatigue behaviour for a 316 L type steel, J. Nucl. Mater. 233-237 (Part 1) (1996) 156-161 (0).

[15] N. Haddar, A. Fissolo, V. Maillot, Thermal fatigue crack networks: a computational study, Int. J. Solids Struct. 42 (2) (2005) 771-788.

[16] V. Maillot, et al., Thermal fatigue crack networks parameters and stability: an experimental study, Int. J. Solids Struct. 42 (2) (2005) $759-769$.

[17] S. Amiable, et al., A comparison of lifetime prediction methods for a thermal fatigue experiment, Int. J. Fatigue 28 (7) (2006) 692-706.

[18] M. Fazarinc, et al., Thermal fatigue properties of differently constructed functionally graded materials aimed for refurbishing of pressure-die-casting dies, Eng. Fail. Anal. 25 (2012) 238-249 (0).

[19] D. Klobčar, J. Tušek, B. Taljat, Thermal fatigue of materials for die-casting tooling, Mater. Sci. Eng. A 472 (1-2) (2008) $198-207$.

[20] D. Klobčar, et al., Thermo fatigue cracking of die casting dies, Eng. Fail. Anal. 20 (2012) 43-53.

[21] D. Caliskanoglu, et al., Thermal fatigue and softening behavior of hot work tool steels, Proceedings of the 6th International Tooling Conference, The Use of Tools Steels, 2002.

[22] H.-W. Song, et al., Thermal fatigue on pistons induced by shaped high power laser. part I: experimental study of transient temperature field and temperature oscillation, Int. J. Heat Mass Transf. 51 (3-4) (2008) 757-767.

[23] D. Mellouli, et al., Thermal fatigue of cast irons for automotive application, Mater. Des. 32 (3) (2011) 1508-1514.

[24] C. Laird, G. Smith, Crack propagation in high stress fatigue, Philos. Mag. 7 (77) (1962) 847-857.

[25] V.S. Bhattachar, Thermal fatigue behaviour of nickel-base superailoy 263 sheets, Int. J. Fatigue 17 (6) (1995) $407-413$.

[26] B.B. Kerezsi, J.W.H. Price, Using the ASME and BSI codes to predict crack growth due to repeated thermal shock, Int. J. Press. Vessel. Pip. 79 (5) (2002) 361-371.

[27] O. Ancelet, et al., Development of a test for the analysis of the harmfulness of a 3D thermal fatigue loading in tubes, Int. J. Fatigue 29 (3) (2007) 549-564.

[28] D. Cong, et al., Thermal fatigue resistance of hot work die steel repaired by partial laser surface remelting and alloying process, Opt. Lasers Eng. 54 (2014) 55-61.

[29] A. Persson, S. Hogmark, J. Bergström, Temperature profiles and conditions for thermal fatigue cracking in brass die casting dies, J. Mater. Process. Technol. 152 (2) (2004) 228-236.

[30] A. Persson, S. Hogmark, J. Bergström, Failure modes in field-tested brass die casting dies, J. Mater. Process. Technol. 148 (1) (2004) $108-118$.

[31] D. Mowbray, D. Woodford, D. Brandt, Thermal Fatigue Characterization of Cast Cobalt and Nickel-base Superalloys, Fatigue at elevated temperatures 1973, p. 1973.

[32] H. Burlet, et al., Crack growth behaviour in a thermal fatigue test. Experiments and calculations, Fatigue Fract. Eng. Mater. Struct. 12 (2) (1989) $123-133$.

[33] G. Tret'yachenko, V. Barylo, N. Solov'eva, Thermal fatigue crack propagation in massive cylinders during their cyclic heating, Strength Mater. 31 (4) (1999) 380-388.

[34] H. Lieurade, et al., Experimental simulation and theoretical modelling of crack initiation and propagation due to thermal cycling, High Temp. Technol. 8 (2) (1989) 137-145

[35] J. Sjostrom, J. Bergstrom, Thermal fatigue in hot-working tools, Scand. J. Metall. 34 (4) (2005) 221-231.

[36] H. Bueckner, Field singularities and related integral representations, Mech. Fract. 1 (1973) 239-314.

[37] F. Rezai-Aria, Fatigue thermique et fatigue isotherme d'un superalliage à base de cobalt: étude metallurgique de l'endommagement et modelisation, 1986 (PhD thesis, UniversitÈ de Paris-Sud, Centre díOrsay, France).

[38] L. Gandossi, N. Taylor, R. Hurst, Crack growth behaviour in 316 L stainless steel components under thermal fatigue loading, Thermal Stresses'99: Third International Congress on Thermal Stresses, 1999.

[39] R.P. Skelton, Fatigue at High Temperature, Applied Science Publishers, 1983.

[40] T. Koizumi, M. Okazaki, Crack growth and prediction of endurance in thermal-mechanical fatigue of 12Cr-Mo-V-W steel, Fatigue Fract. Eng. Mater. Struct. 1 (4) (1979) 509-520

[41] S.-J. Kwon, et al., Damage evaluation regarding to contact zones of high-speed train wheel subjected to thermal fatigue, Eng. Fail. Anal. 55 (2015) 327-342.

[42] F. Qayyum, et al., Comparison of thermomechanical stresses produced in work rolls during hot and cold rolling of cartridge brass 1101 , Mater. Sci. Technol. 31 (3) (2015) 317-324.

[43] E. Paffumi, K.-F. Nilsson, Z. Szaraz, Experimental and numerical assessment of thermal fatigue in 316 austenitic steel pipes, Eng. Fail. Anal. 47 (Part B) (2015) 312-327.

[44] M. Salem, Etude d'endommagement par fatigue thermique des moules de fonderie sous pression d'aluminium: effet de l'interaction avec l'aluminisation et l'oxydation, 2009 (Thesis: Université de Toulouse).

[45] Z. Ahmer, An Investigation on Thermomechanical Behaviour of a Tool Steel X38CrMoV5, ENMP, 2011 Paris.

[46] M. Shah, et al., An estimation of stress intensity factor in a clamped SE (T) specimen through numerical simulation and experimental verification: case of FCGR of AISI H11 tool steel, Acta Metall. Sin. (Engl. Lett.) 25 (4) (2012) 307-319.

[47] N.E. Dowling, Geometry Effects and J Integral Approach to Elastic-plastic Fatigue Crack Growth, ASTM International, 1976.

[48] N.E. Dowling, J.A. Bagley, Fatigue crack growth during gross plasticity and the J-integral, Mechanics of crack growth 1976 , pp. 82-103.

[49] C.L. Chow, T.J. Lu, Cyclic J-integral in relation to fatigue crack initiation and propagation, Eng. Fract. Mech. 39 (1) (1991) 1-20.

[50] S. Sadanada, P. Shahinian, Elastic-plastic fracture mechanics for high temperature fatigue crack growth, Fracture Mechanics: Twelfth Conference, ASTM STP 700 1980, pp. 152-163.

[51] R.M.N. Pelloux, Crack extension by alternating shear, Eng. Fract. Mech. 1 (4) (1970) 697-704.

[52] P. Neumann, New experiments concerning the slip processes at propagating fatigue cracks, Acta Metall. 22 (1973) 1155-1165.

[53] R. Hamam, Simulation de la propagation des fissures par fatigue dans les toiles des roues de train sous chargement à amplitude variable, École normale supérieure de Cachan-ENS Cachan, Cachan, France, 2006237.

[54] C. Schweizer, et al., Mechanisms and modelling of fatigue crack growth under combined low and high cycle fatigue loading, Int. J. Fatigue 33 (2) (2011) 194-202.

[55] A. Standard, E399-90. Standard test method for plane strain fracture toughness of metallic materials, Annual Book of ASTM Standards 3, 1990. 